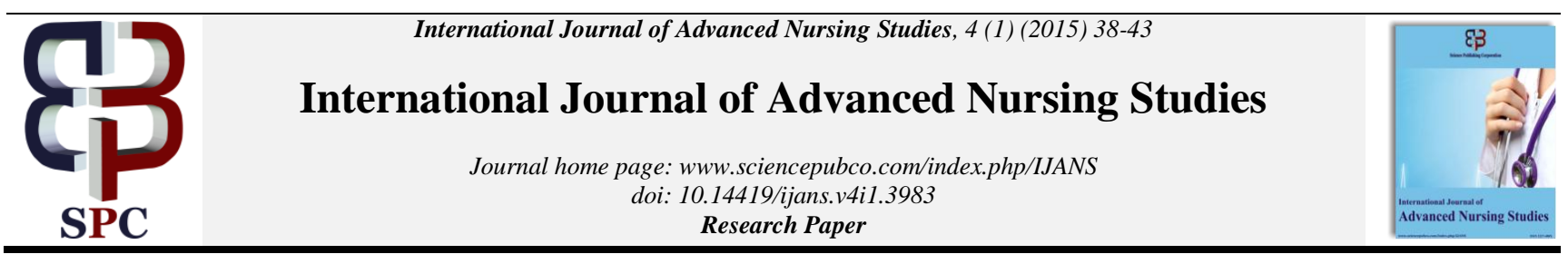

\title{
Conceptual framework for facilitating reflective practice by nurses in the clinical setting
}

\author{
L. N. Nelumbu*, L. Pretorius \\ Institution: University of Namibia, Private Bag 13301; Windhoek; Namibia \\ *Corresponding author E-mail: Inelumbu@unam.na
}

\begin{abstract}
Problems or incidents occurring in clinical settings are often seen as indicators of poor nursing care and even indicators of a lack of reflective practice skills. This paper presents the description of the conceptual framework to facilitate reflective practice for registered nurses in clinical settings. It focuses on the characteristics of the agent (lecturer as a facilitator) and recipients (registered nurses), the context of the clinical practice, the procedures for the facilitation of reflective practice and the terminus or the outcome of reflective practice as may they be demonstrated by quality nursing care for patients.
\end{abstract}

Keywords: Agent; Recipient; Context; Procedure and Terminus.

\section{Background}

This article is extracted from the author's study, “An Educational programme to facilitate reflective practice for registered nurses in training hospitals in Windhoek". The central concept identified in this study revealed that registered nurses lack the knowledge and application of reflective practice in providing care to patients. Hence a conceptual frame work was developed to facilitate learning and application of reflective practice by registered nurses in training hospitals in Windhoek. The conceptual framework was developed based on nursing theory as described by Dickoff, James and Wiedenbach (1968).

The elements of the conceptual framework for this study are the lecturers who should be the agent to facilitate learning and application of reflective practice by the registered nurses as the recipients. In the context of this study knowledgeable registered nurses who are able to provide reflective nursing care are the terminus while the realization of quality care to patients is the dynamics that the agent desires to achieve. Therefore, the lecturer, as an agent developed a programme with interventions to facilitate learning and application of reflective practice for patient care in clinical practice. This conceptual framework is illustrated in the figure below.

\section{2. purpose}

The purpose of the above conceptual map is to illustrate the processes involved in the facilitation process of reflective practice in clinical practice in order to improve the provision of nursing care to patients.

\section{The discussion of the elements involved}

\subsection{Agent: facilitator (researcher)}

An agent is defined in the Oxford Dictionary as "the person or thing that does an action". In the context of this study, the lecturer is the agent who would develop the reflective practice programme for registered nurses in order to improve reflective process in clinical settings. The programme would guide the registered nurses in the clinical setting, to reflect on nursing care interventions and the teaching of students as one of their roles. This in turn results into quality nursing care to the patients.

As a facilitator of changes, the lecturer/agent should possess special characteristics and responsible for specific roles. These include reflective skills, clinical knowledge and skills, educational role, good interpersonal relationship/relationship with the recipients, creative role; and research roles. The next sessions provide the description of the agent's characteristics and how they are applied to the context of this study.

\subsubsection{Reflective skills of an agent}

Reflective practice is described as a cognitive (thinking) process which brings together several stages of deliberate explorations focused on practitioner skills and outcomes (Chong, 2009).

Reflective practice is necessary in the development of the therapist's self-awareness and "therapeutic use of self" by practitioner. It is a pre-requisite of helping others.

In concurrence with the suggestion made by Manning, Cronin, Monaghan \& Rawlings-Anderson, (2009) the programme for reflective practice was developed and implemented to encourage the registered nurses' critical thinking and problem solving. Problem solving and reflective skills dominate the nursing process. Reflective practice includes experiences, knowledge, thinking, feelings before implementation of an action that is appropriate to the patients' conditions. Therefore the literature proves that reflection involves reviewing one's own values, challenging assumptions and considering broader social, political and professional issues that are relevant to the specific patient's condition (Bulman \& Schutz, 2004).

Bulman and Schutz (2004) suggested that self-awareness, description, critical analysis, synthesis and evaluation are the important characteristics the nurse educator should demonstrate as a reflective practitioner. 


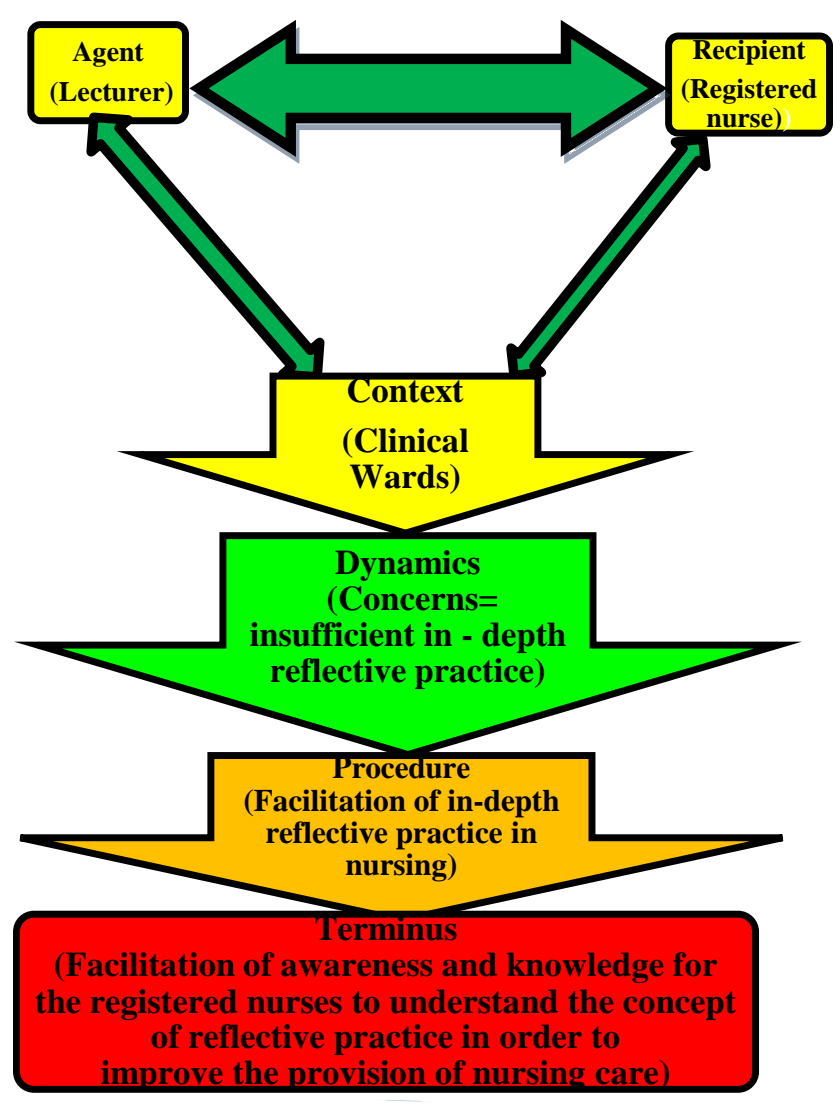

Fig. 1: Conceptual Map of Reflective Practice

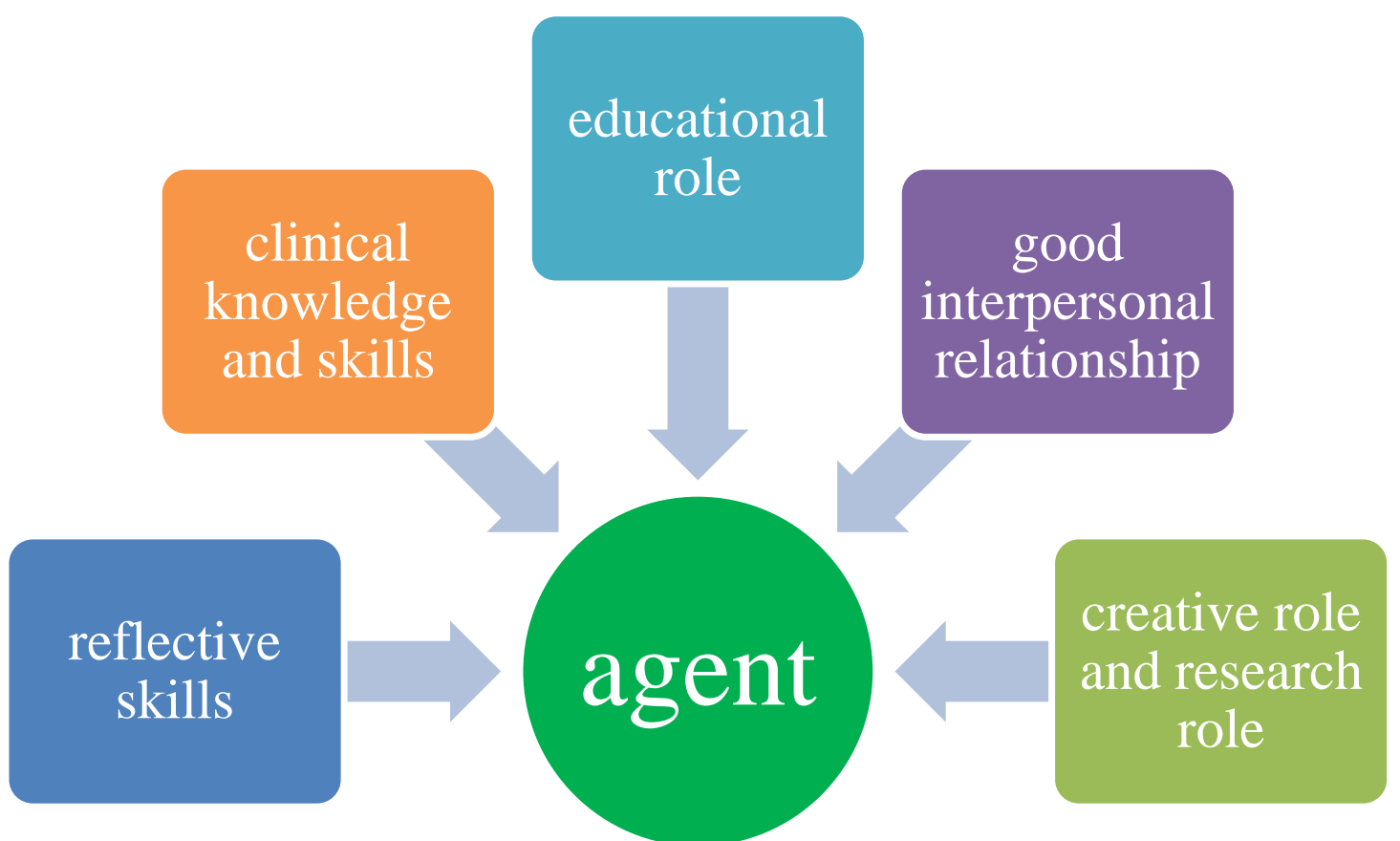

Fig. 2: The Characteristics of an Agent

\subsubsection{Clinical knowledge and skills}

The nurse educator or lecturer should possess adequate clinical knowledge and skills. This trait is very important as it implies that a nurse educator or lecturer aids the registered nurses and students to identify, mobilize and develop their own strengths in clinical practice-in particular, the concept of reflective practice. A knowledgeable nurse educator would serve as a role model to other col- 
leagues in the teaching and nurse education sector as well as in the clinical setting by showing his/her competency and professionalism, by being a skilled person and by showing him/herself to be a dedicated person.

Nurse educators should also pay attention to their educational role and instructional ability. Their skills must include competency in teaching that is, knowing how to deliver the clinical and subject content to the students and colleagues in a clinical setting with the aim of providing quality care to the patients. It is also expected that nurse educators should be able to provide timely, constructive and specific feedback concerning practical skills and knowledge of the course to their colleagues as well as to students. The nurse educator or lecturer should be involved in course planning, designing clinical experiences for students and participating in teaching in the clinical area, as well as providing advice to other professionals in clinical settings in order to keep up the standards of nursing care.

The above mentioned statements are supported by Lathlean (1997) who holds that as in everyday life, our knowing is embedded in our action, and reflection-in-action involves making conscious the tacit 'knowledge' incorporated in the routines of practice, and subjecting that 'knowledge' to critical examination, to make sense of situations of uncertainty and uniqueness.

\subsubsection{Educational role}

The educational role of the lecturer or nurse educator can be seen as the role of an educational manager of practice. In the context of this study the role of the lecturer as a facilitator is to ensure that other practitioners within the organization generally and deliberately act as models or examples for the learners; she needs to have the ability to draw on resources, especially other people, in the provision of educational opportunities for the learner, and above all to possess a clear conception of what is required to develop the learning environment (Lathlean 1997).

A lecturer's attitude and enthusiasm have an important effect on the students' motivation. It is therefore in this regard, that the researcher proposes the implementation of reflective practice programme as an effective educational strategy to assist in facilitating reflective practice for both registered nurses and novice nurses/student nurses. In conclusion, facilitation of reflective practice assists the student nurses to learn and grasp the patients' specific needs and to generalize experiences from similar situations (Forneris and Peden-McAlpine 2009), Skar 2010).

As a result, the students develop practical skills during clinical training within various clinics, hospitals and health centres and in community care, the experiences which they would apply as qualified nurse practitioners to provide quality care to the patients (Lindahl, Dagborn and Nilsson 2009).

\subsubsection{Interpersonal skills}

'Interpersonal skills' of a nurse educator refers to those interpersonal aspects of communication and social skills that she/he (needs to) use in direct person-to-person contact with the nurse practitioners and students. Employment of good professional interpersonal skills by the nurse educator enables effective facilitation of changes for quality care to patients (Kagan and Evans (1995).

This implies good mentoring approaches, objective motivation, non-judgmental support, as well as a respectful attitude toward his/her colleagues, as well as students in clinical practice.

\subsubsection{Research role}

As an agent of changes, the lecturer should develop researchbased knowledge, to refine existing knowledge and generate knew knowledge that directly and indirectly influence clinical nursing practice (Burns \& Groves, 2005).

Consequently, in the context of this study, the nurse educator should encourage the registered nurses and students to explore and identify knowledge for the improvement of patient care in clinical setting. Both collaborative and individual approaches need to be encouraged with the aim of improving health, moving toward holistic health and quality care.

In conclusion, clinical knowledge and skills, the educational role, good interpersonal relationships and creative and research roles are some of the prominent characteristics of an agent imbedded in reflective practice and which are suggested for the improvement of nursing care in the clinical setting.

\subsection{Recipient/registered nurse}

A recipient can be defined as the beneficiary of the interventions. In the context of this article, the recipient is a registered nurse who provides nursing care to the patients in the wards; therefore clinical knowledge and skills are important to her/him. As the agent develops the reflective practice programme, the registered nurses are expected to adopt this programme and implement it in order to improve their reflection in clinical practice.

Registered nurses should have good interpersonal relationships in terms of respecting their subordinates and having trust in them. They need to exhibit good communication and active listening skills. Registered nurses should accept responsibility and accountability for teaching and supervision, as well as an advisory role to those working under them. It is also important for a registered nurse to serve as a role model to colleagues as well as his/her patients.

For the realisation of reflective practice, registered nurse should display the following characteristics: reflective skills, clinical knowledge and skills and teaching role, coordination and collaboration, communication and active listening skills, leadership and management role and empathy as displayed in figure 3 below and discussed in the next sessions.

\subsubsection{Reflective skills of recipient}

Registered nurses should be responsive and reflective in their practice. This can only be achieved by fostering critical thinking and self-awareness in clinical aspects.

It is important for registered nurses to have an understanding of the word 'reflection' which according to Lindahl et al. (2009) means 'a bending or turning back'.

\subsubsection{Clinical knowledge and skills and the teaching role}

Practical knowledge is seen as "knowing how", which is gained by experience from practical training and performing interventions (Ehrenberg \& Haggblom, 2007). Thus learning from experience through reflection would promote effective learning. Practical knowledge is a very important aspect of clinical practice. It is therefore essential that registered nurses should assist student nurses in clinical settings to learn. Registered nurses need to be educated about how to engage students or new nurses to think at higher levels. Moreover, registered nurses should provide information, advice and emotional support to a junior person or student over a period of time (Lev, Kolassa and Bakken (2010). 


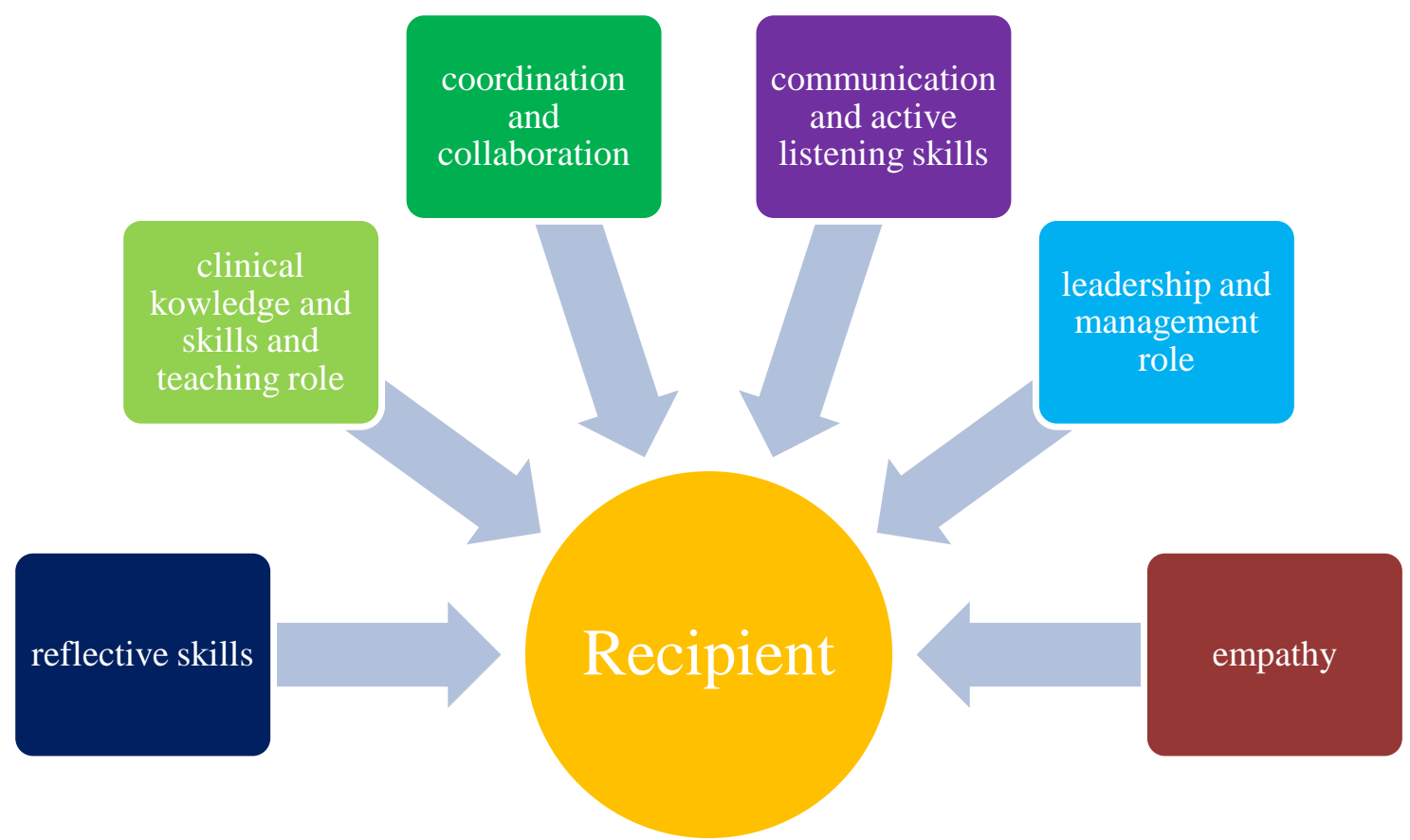

Fig. 3: The Characteristics of the Recipient (Registered Nurse)

\subsubsection{Coordination and collaboration}

It is very important for registered nurses to realise and understand that within their working environment they need proper coordination of activities and collaboration with all other health professionals in order to enhance quality care to patients. Therefore in fostering collaboration and cooperation with multidisciplinary team they need to communicate with interdisciplinary team members and be able to facilitate movement of patients across health care settings.

Nursing care alone is not regarded as sufficient care for patients. It needs other hands from allied health professionals, for example, doctors, pharmacists, occupational therapists and physiotherapists, as well as nurse educators or lecturers who are responsible for student teaching in clinical settings. It is therefore important to promote collaboration so that all those responsible for patient care can be able to examine the effects and results of all activities meant for the provision of care to the patients. This can only be achieved through regularly scheduled times, such as monthly team meetings and staff development meetings. Multiple viewpoints are effective in terms of the improvement of patient care.

\subsubsection{Communication and active listening skills}

Registered nurses as recipients of the reflective practice programme need to demonstrate sound communication and listening skills to share knowledge and skills of patient care to their delegates (Searle \& Pera 1992). Furthermore registered nurses should apply listening skills to interpret the patients' verbal and nonverbal signals of need for care. As a result, registered nurses should employ reflective practice for effective health care outcomes and therefore provision of quality care to patients (Burnard 2000, Kagan and Evans 1995, Mapanga and Mapanga 2008).

\subsubsection{Leadership and management role}

In performance of clinical care, registered nurses should perform managerial role while displaying leadership. In that regard registered nurses should demonstrate good leadership skills through giving of clarity of work or task to be performed for patient care, have a strong sense of task planning, implementation and evaluation of care given. Indeed as the literature proposes as leaders in the clinical settings, registered nurses should be able to perform the multifaceted process of identifying a goal, motivating other care practitioners to act and providing support and motivation toward achievement of set goals (Walker, Cooke, Henderson and Creedy 2011).

\subsubsection{Empathy}

'Empathy' is the ability to understand another person's feelings and experiences. This aspect is very important in the provision of care situations. Registered nurses should develop a sense of such understanding so that they may be able to provide proper and effective care to patients. On the other hand, empathy can also be demonstrated within the relationship among staff members. It can be seen in the light of understanding of others' strengths and weaknesses. It means that registered nurses should understand others and try to assist them so that they can learn a better way of providing better nursing care.

In summary, the author discussed in this section the characteristics which are required of a recipient who in the context of this article is a registered nurse. These involve clinical knowledge skills, coordination and collaboration, communication and active listening skills, leadership and management roles as well as empathy.

\section{Context}

'Context' is the situation in which the interventions take place and that helps you to understand. Context can also influence the intended interventions. In the perspective of this article, context refers to the clinical settings where registered nurses apply reflective practice in order to improve their practice for quality patient care.

As a clinical environment the context is a place where interaction with clients and families are taking place for the purpose of providing care. Therefore registered nurses should employ the cognitive skills, such as problem solving, clinical decision making and psychomotor and affective skills to provide quality care to patients.

\section{Dynamics}

'Dynamics' is a force that produces change, action or effects. In the context of this study, dynamics are the desired ability of the registered nurses to competently apply reflective practice in providing care to the patients and guiding student nurses toward the 
competence. Registered nurses are playing a very important role in clinical practice. Therefore, they are to implement reflective practice during their daily practice. The reflective practice (in- and onaction) should become the process for improvement of clinical practice. Nevertheless, implementation of reflective practice requires employment of managerial skills and resources. These include securing good facilities, materials, guidelines, strategies and policies, as well as knowledgeable and skilled personnel.

\section{Procedure}

'Procedure' refers to a written, approved specification for execution of an activity - often composed of steps using established methods or forms designed to achieve a uniform approach in compliance with applicable policies or directives. For the purpose of the implementation of reflective practice, the researcher proposes procedures that are to be implemented for the registered nurses to learn and apply reflective practice in patient care. The implementation of these procedures can build the registered nurses, capacity for critical thinking and reflective practice for patient care. As a result these improve quality care to patients and the desired end result.

\section{Terminus}

'Terminus' is the final goal or finishing point of the process. The purpose of this article is to develop a conceptual framework for facilitation of reflective practice programme for registered nurses in clinical settings. Registered nurses should adopt and implement this programme in order to understand the reflection-in-action during the activity and reflection-on-action after the performance of the activity. These are the important components of reflective practice which can be applied in order to improve the registered nurses' daily practice for the provision of quality nursing care. Here the feedback or the output is expected from both parties-the giver (an agent) and the receiver/recipient. The outcome of this would be the proper implementation or application of reflective practice based on proper knowledge and skills which lead to provision of quality patient care (see Figure 4 below).

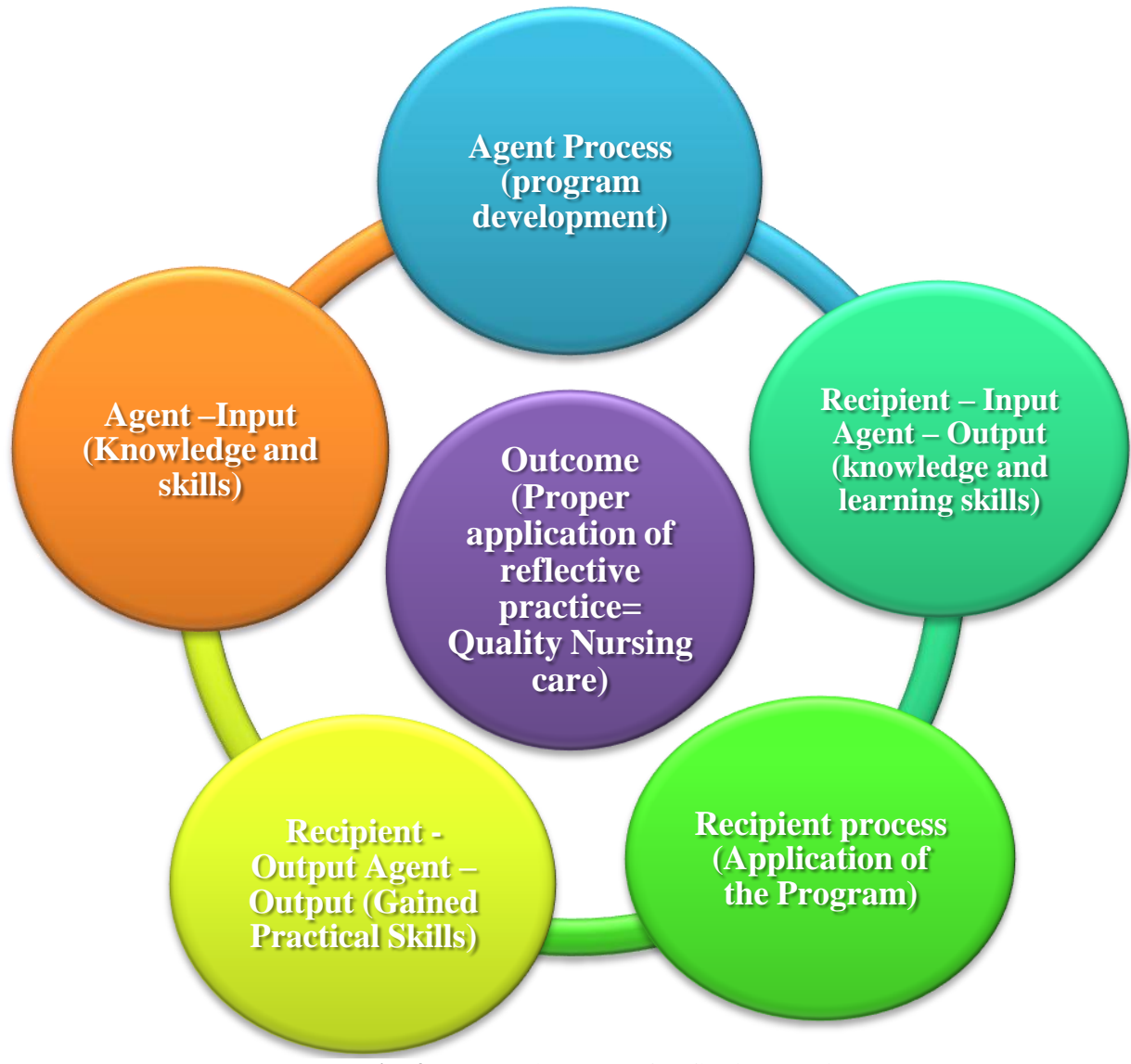

Fig. 4: Structural Process of Reflective Practice

\section{Conclusion}

This article has defined and discussed elements of conceptual framework for the proposed reflective practice programme. The elements are identified as an agent-the facilitator of the programme; the recipient-the beneficiaries from the programme intervention; context-the clinical settings for the implementation of the reflective practice programme; procedure-specific interventions for learning reflective practice by registered nurses; dynamics-the desired quality care to patient as a result of terminuscompetent registered nurses who are able to apply reflective practice for patient care.

Based on the discussions of the above-mentioned elements, the researcher has identified and developed the structural process of reflective practice which entails the input and output of an agent and the input and output of the recipient, which lead to the desired outcome - the proper application of reflective practice with quality nursing care as the end product.

\section{Acknowledgements}

This article has been extracted from the author's study "An Educational programme to facilitate reflective practice for registered nurses in training hospitals in Windhoek" with the permission of the Ethical and Research Committee of the Ministry of Health and Social Services in Namibia. Special thanks are extended to the person who proof read this article. 


\section{References}

[1] Bulman, C. \& Schutz, S. (2004). Reflective practice in nursing. Oxford: Blackwell Publishing.

[2] Burnard, P. (2000). Using experiential learning methods with larger group of students. Nurse Education Today, 13 (1) 60-65. http://dx.doi.org/10.1016/0260-6917(93)90010-Y.

[3] Burns, N. \& Grove, S. K. (2005). The practice of nursing research: Conduct, Critique and Utilisation. St. Louis: Elsevier Saunders.

[4] Chong, M. C. (2009). Is reflective practice a useful task for student nurses? Asian Nursing Research, 3(3), 111-120. http://dx.doi.org/10.1016/S1976-1317(09)60022-0.

[5] Dickoff, J., James, P., \& Wiedenbach, E. (1968). Theory in a practice discipline, part 1: Practice orientated theory. American Journal of Nursing Company, 17(5), 438-488.

[6] Ehrenberg, A. \& Haggblom, M. (2007). Problem-based learning in clinical nurse education: Integrating theory and practice. Nurse Education in Practice, 7(2), 67-74. http://dx.doi.org/10.1016/j.nepr.2006.04.005.

[7] Forneris, S. G. \& Peden-McAlpine, C. (2009). Creating context for critical thinking in practice: the role of the preceptor. Journal of Advanced Nursing, 65(8), 1715-1724. http://dx.doi.org/10.1111/j.13652648.2009.05031.x.

[8] Kagan, C. \& Evans, J. (1995). Professional Interpersonal Skills for Nurses. Cheltenham: Stanley Thornes. http://dx.doi.org/10.1007/9781-4899-4463-4

[9] Lathlean, J. (1997). Lecturer Practitioners in Action; Oxford: Butterworth-Heinemann.

[10]Lev, E. L., Kolassa, J. \& Bakken, L.L. (2010). Faculty mentors and students' Perceptions of students' research self-efficacy. Nurse Education Today, 30(2), 169-174. http://dx.doi.org/10.1016/j.nedt.2009.07.007.

[11]Lindahl, B., Dagborn, K. \& Nilsson, M. (2009). A student-centred clinical educational unit: Description of a reflective learning model. Nurse Education in Practice, 9(1), 5-12. http://dx.doi.org/10.1016/j.nepr.2008.03.008.

[12] Manning, A., Cronin, P., Monaghan, A. \& Rawlings-Anderson, K. (2009). Supporting students in practice: An exploration of reflective groups as a means of support. Nurse Education in Practice, 9(3), 176183. http://dx.doi.org/10.1016/j.nepr.2008.07.001

[13]Mapanga K. G. \& Mapanga, M. B. (2008). A modern Africa Perspective on Rote of the Clinical Nurse Specialist. Journal of Advanced Nursing, 22(5), 226-230 Oxford Dictionary (2005) Oxford: University Press.

[14]Skar, R. (2010). Knowledge use in nursing practice: The importance of practical understanding and personal involvement. Nurse Education Today, 30(2), 132-136. http://dx.doi.org/10.1016/j.nedt.2009.06.012.

[15]Searle, C. \& Pera, S. (1992). Professional Practice: A South African Nursing Perspective. Durban: Butterworths.

[16]Walker, R., Cooke, M., Henderson, A. \& Creedy, D. K. (2011). Characteristics of leadership that influence clinical learning: A narrative review. Nurse Education Today, 31(8), 743-756. http://dx.doi.org/10.1016/i.nedt.2010.12.018. 